\title{
Implementing a university e-learning strategy: levers for change within academic schools
}

\author{
Rhona Sharpe*, Greg Benfield and Richard Francis \\ Oxford Brookes University, UK
}

This paper describes the implementation of an e-learning strategy at a single higher education institution in terms of the levers used to promote effective uptake and ensure sustainable embedding. The focus of this work was at the level of the academic school using a range of change practices including the appointment of school-based learning technologists and e-learning champions, supporting schools to write their own strategies, a pedagogical framework of engaging with e-learning, and curriculum development and evaluation of school-supported projects. It is clear that the implementation of the e-learning strategy has led to a large and increasing proportion of our students experiencing blended learning. In addition, there are initial indications that this has enhanced some learning and teaching processes. Where there has been sustainable embedding of effective e-learning, the following levers were identified as particularly important: flexibility in practices that allow schools to contextualise their plans for change, the facilitation of communities of key staff and creating opportunities for staff to voice and challenge their beliefs about e-learning.

\section{Introduction}

There have been many attempts to identify what is needed to promote the adoption of technologies within higher education institutions. There are commonly recommendations for leadership, technology infrastructure, institutional vision and provision of resources (for example, Wills \& Alexander, 2000; Banks \& Powell, 2002; Garrison \& Anderson, 2003). Within our own institution, and many others, such advice has led to the creation of a learning media unit, the purchase of an institutionally supported virtual learning environment (VLE) and the development of an institutional e-learning strategy. This is not unusual. In a recent UK survey, Browne and Jenkins (2003) found that $86 \%$ of higher education institutions that responded to the survey now have at least one VLE in use. However, both Browne and Jenkins and a

\footnotetext{
*Corresponding author. Oxford Centre for Staff and Learning Development, Oxford Brookes University, Wheatley Campus, OX33 1HX, UK. Email: rsharpe@brookes.ac.uk
} 
similar study conducted by Bell et al. (2002) in Australia report that, although VLE use is widespread, it is predominantly supplementary, optional for students and does little to change the patterns of learning and teaching. To illustrate the scale of the problem, Lee (2004) shares figures about VLE usage in his own Australian institution, admitting that in an examination of 700 online courses less than one-half were using discussions and less than one-third using formative assessments. Our challenge then is not promoting uptake, but facilitating effective implementation across an institution that is likely to impact on student learning in significant ways.

By 2002, Oxford Brookes was in a similar position. By this time we had created our Media Workshop, rolled out a VLE, appointed a Head of E-learning, supported a number of pilot projects and had the beginnings of an institutional strategy for elearning. As we had hoped, the usage figures for our institutionally supported VLE were showing impressive increases in requests for new courses. Yet-with some notable exceptions - the bulk of this use was relatively unsophisticated and focused on content delivery. We recognised that this is a dangerous position to be in. Newton (2003), taking an ethnographic approach to the implementation of a learning and teaching strategy at a single UK university, found that patchy implementation, evidenced by missed deadlines and targets, influenced academic perceptions of the value of having a strategy at all. Our concern was that lack of sustained and effective implementation could lead to e-learning developments being dropped when the next initiative came along.

The task was to put together an institutional implementation plan that would result in sustainable and effective uptake of technologies that improved the student experience. There are a large number of development tools and processes on which to draw and we were keen to develop an implementation programme that was based on the evidence emerging from the literature. This paper explains the rationale for the methods we chose, describes how they were implemented and draws on our experiences and existing evaluative data to make recommendations about which methods were most successful and worthy of further investigation.

The Browne and Jenkins survey showed that the most frequently used development tool for supporting VLE use is still project funding often associated with staff time release. Supporting individuals through project funding can support the development of innovative practices (Hannan \& Silver, 2000) and we had already funded a number of pilot projects previously (Challis \& Lidgey, 2000). We considered instead approaches undertaken by institutions to promote the effective and/or sustainable use of e-learning. These appear to be many and varied, and include accredited professional development programmes (Beetham \& Bailey, 2002), bringing 'pioneers' together at University of Twente (Collis \& De Boer, 1999), understanding individual lecturers' motivations to make use of technology at Bournemouth (Hanson, 2003) and the Computer Supported Experiential Learning curriculum re-design model used at University of Central England (Staley \& MacKenzie, 2001). Which of these might be successful and worth pursuing?

Oliver and Dempster (2003) reviewed a number of such different initiatives for developing e-learning practice and concluded that: 
There appears no ready model—no single, clearly successful path—that ensures e-learning will be embedded. The operational context is thus crucial to the choice of tactics that are likely to lead to success. (p. 144)

More recently, Stiles (2004) has argued persuasively that:

Clearly understanding where you are starting from is as important as understanding where you want to get to. Expanding the use of eLearning in an institution requires a clear and honest analysis of the organisation in terms of strengths and weaknesses viewed against its strategic goals. (p.14)

We would agree that consideration of context is essential in the planning of any institution-wide change programme. The first stage of developing the implementation programme was to conduct such a deliberate analysis of our current institutional context.

\section{An initial analysis of context}

Oxford Brookes University is a post-1992 UK university with a longstanding international reputation for supporting educational innovation, student-centred learning and promoting e-learning. Oxford Brookes has been particularly good at supporting early adopters of learning technologies. Examples include such initiatives as IT Term (Baume, 1996), the funding of 11 Brookes Virtual projects (Challis \& Lidgey, 2000) and the founding of the Media Workshop in 2000. Our innovators are energetic and support pockets of good practice around the university. For example, in July 2002 we had hosted our second biennial internal one-day conference on e-learning with over 100 attendees. Many of these people had success stories to show and tell, and their enthusiasm for their work with e-learning was a powerful motivation to others. Their contribution to the change achieved to date is not to be underestimated and we saw a clear need to recognise and reward the efforts of these individuals, as well as to make their lives easier.

Brookes has a highly federated structure with semi-autonomous schools that develop their own initiatives and directions. Consequently, in the early stages of VLE implementation, different schools developed e-learning in different directions. For example, some were interested in reusable content, others were mostly concerned with communicative technologies and yet others with computer-aided assessment. Neither the university nor schools had specific objectives for e-learning. E-learning development was focused on central support for the initiatives of the individual enthusiasts and early adopters. By 2002 it was clear that we needed to move e-learning into the mainstream. A head of e-learning was appointed and a task group was convened to develop a university-wide e-learning strategy to replace the previous Brookes Virtual project plan. This was approved in November 2002 as an annexe to the university Learning, Teaching and Assessment strategy.

Given this institutional context, the programme of implementation was focused around our aims to: 
- develop ownership and commitment to the university strategy at the departmental level;

- harness the energy of our innovators to drive change forward;

- support staff to make educationally sound choices about using technology; and

- involve heads of school and other senior managers, starting by making them aware of the groundswell of energy and good practice already occurring.

\section{A pedagogical framework for engaging with e-learning}

The university e-learning strategy was deliberately short on targets. The only easily identifiable target was that all courses should have some kind of web presence by September 2004. This type of target is common; for example, Lisewski (2004) reports that Salford University required that all modules should use the Blackboard VLE to establish a web presence. In their survey, Browne and Jenkins (2003) report that this was actually the most common type of target in implementation strategies. However, they also point out that setting such a target may not allow for examination of reasons for using technology and may reflect bulk registration of courses. Our target differs from these in two crucial ways: first, it did not require use of the institutional VLE and, second, it did not relate to modules, using the more vague term of 'courses'. This allowed-indeed encouraged-discussion of precisely what the target meant. Although this was uncomfortable at the time, in retrospect it was very useful to engage schools in this debate.

Despite this $100 \%$ usage target, our interest is not in promoting the use of e-learning for its own sake, but in improving the student experience by incorporating e-learning effectively into teaching. Although there is evidence of the e-pedagogies that can support student learning, the literature is complex and at times contradictory and academics can find it overwhelming (Conole et al., 2004). We wanted to support staff to engage with discussions about how best to make use of technology and offer them some simple guidance about what are known to be effective strategies. To keep learning design at the very centre of discussions about e-learning, we developed a pedagogic framework for e-learning that we called the 'modes of engagement' (see Figure 1). This allowed us to codify what are considered to be effective e-learning practices and present this in a way that was easily accessible to academics.

The modes of engagement framework was initially produced to allow us to engage in conversations with course teams about what they want to do. In fact, it has had a much wider impact. It has become a focus and a structure for staff support and development. For example, all staff development workshops are labelled by the mode they best support. Central data captured about WebCT courses now routinely include categorisation by mode. For example, the online 'Go Live' process by which staff request that their WebCT development site be transferred to a live course for use by students requires description of the mode and the type of pedagogic enhancement being implemented. A database holding all the central data about WebCT courses has been enhanced by schools auditing WebCT use and adding descriptive, pedagogic data to the usual information about registered students and module codes. 


\section{Mode 1}

baseline course administration and learner support

Use web to distribute course information and carry out course administration (chosen from the following): aims and objectives, assessment criteria/proformas, past exam questions and model answers/assessment sheets, timetabling announcements, reading lists, tutor contact details, course evaluation tools, FAQs, additional web resources, links to field level resources, course/module handbook, lecture notes.

\section{Mode 2}

blended learning leading to significant enhancements to leaming and teaching processes

\section{Communication}

Provide improved tutor-student, studentstudent communications, mainly using discussion boards or email. Enable students, especially in disparate groupings and locations, to exchange information, ask questions and discuss issues relating to the course.

\section{Collaboration}

Provide a platform for collaborative student projects, involving shared responsibility for resources and outcomes. Students use communication tools and shared directory to collaborate on task processes and outcomes.

\begin{abstract}
Assessment
Provide improved feedback to students on their learning via computer assisted assessment for either formative (selfassessment and monitoring of progress) or summative (examination and grading) purposes or both. May involve electronic setting, submission and return of student assignments using digital artefacts and proformas where objective testing inappropriate.
\end{abstract}

\section{Learning content}

Develop flexible access to high quality. reusable learning content, which may include structured gateways to web and other resources with accompanying self-paced independent learning activities, interactive tutorials with feedback, simulations, study and learning skills resources and activities fostering independent leaming.

\section{Mode 3 \\ on-line courseimodule}

Develop module/course incorporating all or most of the above that can be delivered flexibly to allow leamers to learn at times and places of their choosing. Likely to include presentation of course materials, communication between tutor and students, selfassessment and monitoring of progress.

Figure 1. E-learning modes of engagement

Figure 2 shows an example of this. Such data allow us to easily locate modules using for example, WebCT communication tools or formative assessments and provides a common reference framework for evaluation. 


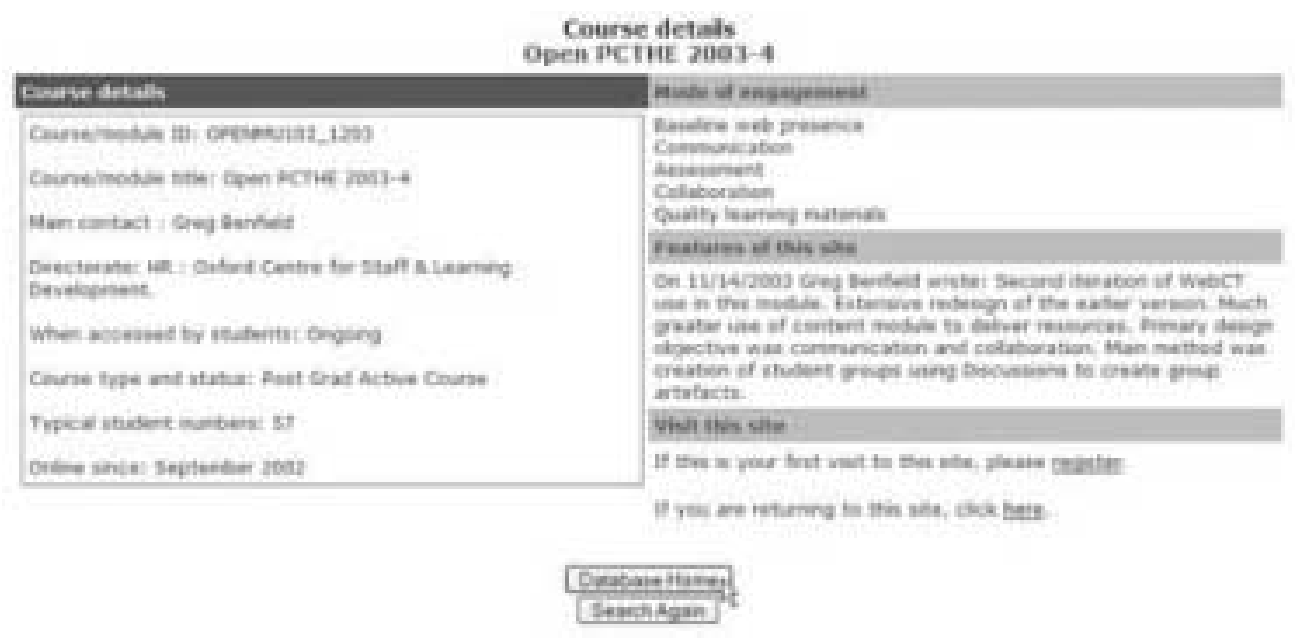

Figure 2. Example of data held about a WebCT module, including mode of engagement

\section{E-learning champions}

Reward is seen as crucial for any e-learning initiative although there has been some debate over what are considered the most appropriate rewards, including promotion, accreditation or opportunities to publish (Beetham \& Bailey, 2002; Oliver \& Dempster, 2003). In our strategy we opted for promotion requiring the appointment of an e-learning champion within each of the eight academic schools. The appointments were generally unproblematic in that there were often obvious candidates from among existing early adopters. Often this was the first formal reward for innovators that recognised long-standing activity and rewarded success in e-learning. Having a named group of innovators also raised the profile of e-learning in the university.

Although we had supported innovators before, we had not given them a schoolwide remit to champion the use of technology. There was evidence coming from Coventry University of the success of their learning and teaching 'task force'. Here 26 academics were not only released from teaching to conduct innovative projects, they also had a larger mission to effect change at school and institutional levels (Beaty et al., 2002). We provided schools with suggestions of roles for champions, including to:

- write an e-learning strategy for their school;

- identify local areas of action;

- collate and disseminate good practice in e-learning;

- contribute to research and publication related to e-learning; and

- consider staff development needs for the school using a cascade model.

We were keen that our e-learning champions would input to institutional strategy, starting with writing an e-learning strategy for their own school that would be owned, local and relevant. Providing a learning technologist, often managed by the champion, aimed to create a local power base, providing authority, support and resources. 


\section{Learning technologists}

The e-learning strategy also included the appointment of a learning technologist within each academic school. These appointments turned out to be more complex than the champions. This was a new role, the only precedent within the university being the Media Workshop staff and there were vigorous debates about their roles and relationships with academic staff. Building on previous national work (Oliver, 2002) we provided schools with a template for a job description and person specification, and sat on interview panels on request.

The school-based learning technologists have the potential to be a powerful group and it was necessary to coordinate their activities in some way to ensure that their impact was felt across the whole institution and not solely within their school. The Media Workshop took on responsibility for the staff development and later career development of this group, beginning by hosting a monthly learning technologist forum on Friday lunchtimes. As the primary function of this was to induct the learning technologists into their new roles and help them develop the skills they would need to perform these effectively, we sought support from the university Human Resources strategy to fund their time commitment for a half-day per week. On appointment, each school was given this small amount of money for their learning technologist to attend the forum regularly.

\section{School-level e-learning strategies}

In his influential guide to good practice in implementing institutional learning and teaching strategies, Gibbs (1999) argues that institutions need to concentrate on how strategy is developed, over and above what it says. Accordingly, the e-learning strategy attempted to employ both top-down and bottom-up approaches to implementation (Fitz et al., 1994; Trowler, 1998). As well as specifying central objectives for the university, it put forward initiatives designed to encourage school management buy-in to e-learning and to elicit bottom-up activity. A key plank of this approach was the recommendation that each school develop, publish and maintain their own e-learning strategy. These mechanisms encouraged schools to debate and explore how they could use technologies to achieve their own and the university's goals and allowed staff to articulate and voice their beliefs about teaching and learning with technology.

We were aware of previous findings that creating communities of innovators may not achieve real change, but just create separate communities (Oliver \& Dempster, 2003), so involving the e-learning champions in this process aimed to empower them as leaders in innovation in teaching and learning and embed their work into departmental practices. However, it quickly emerged that the individuals and in many cases groups tasked with developing school strategies needed support, and we produced and distributed a template for a school strategy. The template comprised sections on: background and rationale, goals and outcomes, evaluation and dissemination and resources. We answered questions quickly as they emerged and often made the 
answers public. The template was distributed with a covering memo that clearly explained why they had been asked to do this and what the benefits would be.

The section on goals and outcomes asked schools to identify which developments they wanted to support. We asked schools to pick a small number (usually three to five) of high impact projects to focus their developments on. High impact has often meant choosing large, level 1 undergraduate modules or programme-wide initiatives that will affect many students, courses with which many of the school staff are involved in teaching or those courses that fit well with the school's wider strategic plan.

Following Laurillard's (2001) advice about promoting action research with results that can be fed back into the course design process, the final section of the template for school e-learning strategies asked schools to think about how they would evaluate their e-learning implementations. Evaluation encourages a critical discourse about what works and supports staff to continuously improve their practice, as well as giving valuable stories for dissemination throughout the institution.

\section{Targeted staff development}

It was seen to be a crucial part of the implementation of the university e-learning strategy that staff development was planned and used effectively so part of the schools strategy template included making plans for staff development. When asked to make requests for staff development, schools' first response was often to ask for WebCT training for all staff. This type of training is directed at the individual, largely abstracted from their working practice. Participants in them go away and soon forget how to do the things they have been shown. By contrast, it was felt that 'learning-inworking is an occupational necessity' (Seely-Brown \& Duguid, 1991, p. 43). We thus spent a lot of time helping schools to plan appropriate staff development linked to their school supported projects.

Identifying the school-supported high-impact projects allowed us to target our staff development where needed. As a result of this we have been able to organise working directly with course teams on key school-supported projects, devising staff development opportunities that stress learning by doing. Once a school-supported project has begun, the course teams are invited to come on the two-day course (re)design intensive experience with their expanded course team including their learning technologist and e-learning champion. This event recognises that e-learning courses need high levels of planning. We take course teams through a guided planning process supported by such tools as blue skies thinking, storyboarding and risk assessment, culminating in presentations to critical friends. This follows the type of planning recommended by the Embedding Learning Technologies programmes, which resulted from the EFFECTS project (Stiles \& Yorke, 2003) and supports the development of non-technical skills needed including curriculum development, evaluation and resource planning that support all course team members to take on new roles (Dempster \& Deepwell, 2003).

We also worked with the Director of Human Resources to link the resources section of the template to overall school staff development plans and-importantly-its 
funding. In the second year of operation, this link has become even stronger as we have shifted our timing to coincide with the writing of school staff development plans and asked all plans to include a statement about e-learning.

\section{Evaluation and discussion}

The evaluation is primarily concerned with the success of implementing the e-learning strategy and identification of development activities that were instrumental in this process. The evaluation section draws on existing data to assess the relative effectiveness of the implementation methods adopted and explore what might underpin effective activities for embedding e-learning. In addition, we offer three illustrative examples of detailed evaluations being conducted with the course teams from schoolsupported projects, which explore the learner and tutor experiences and aim to demonstrate enhancements to learning and teaching through Mode 2 developments.

\section{Use of the institutional VLE}

Student use of the VLE has increased dramatically over the previous two years (see Figure 3). Currently, approximately 15,000 of the university's 18,000 students ( $83 \%$ ) are using the VLE for at least one of their courses. The number of new courses created in September each year has also been recorded (see Figure 4). It is likely that the increase in the requests for new WebCT courses in the period leading up to and including September 2004 was largely a response to the university target for all courses to have a web presence by this date. As of the end of March 2005, Brookes had 1100 WebCT courses with over 65,000 student-course relationships. This represents an average of just over three WebCT modules per student in the university.

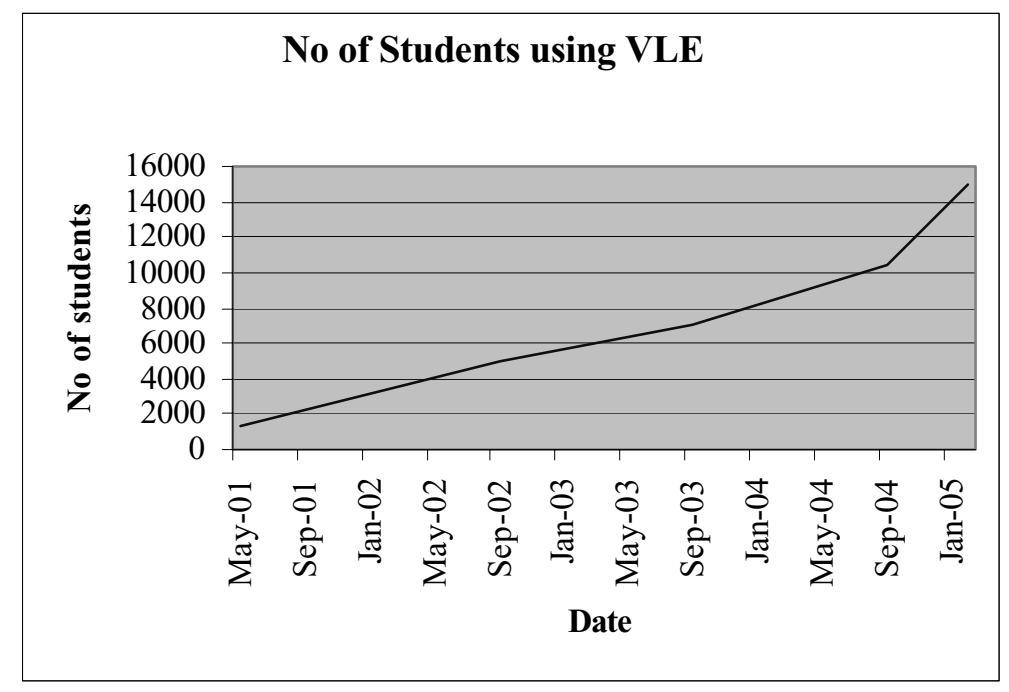

Figure 3. Number of students using the institutional VLE (2001-2005) 


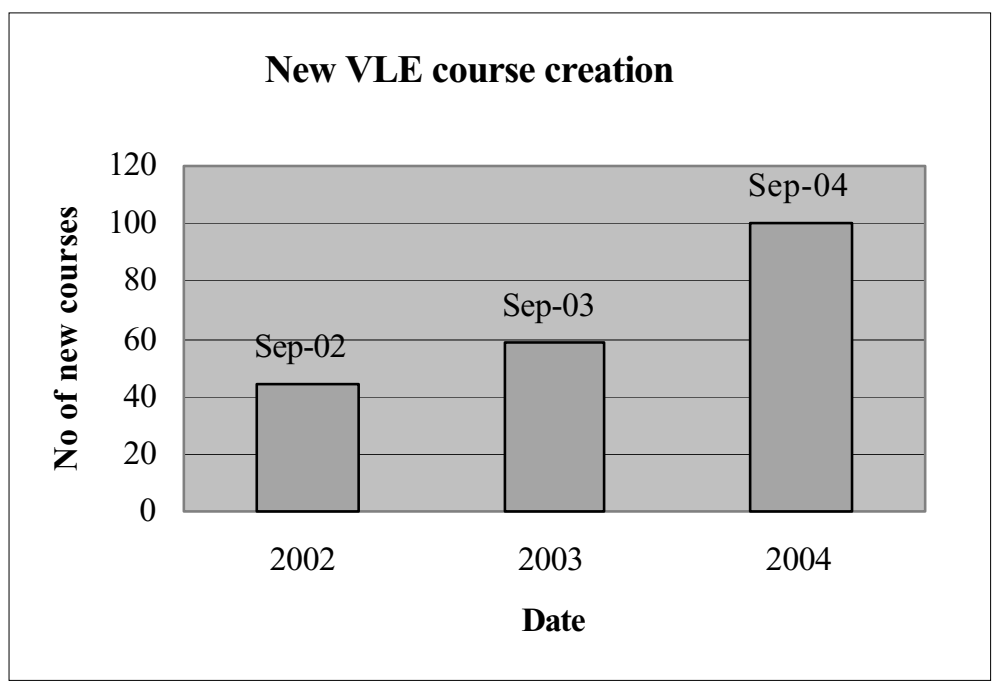

Figure 4. Number of new courses created on the institutional VLE

\section{Examples of effective use}

To illustrate the type of use being made of the VLE, three high-impact schoolsupported projects are described in the following in relation to the modes of engagement framework (see Figure 1). We have followed these initiatives for more two years from their initial identification in school strategies, through planning the staff development requirements, working with the course teams on the course design two-day intensive experience and supporting the learning technologists to develop the specific skills they would need to implement the course teams' designs. This level of involvement with course teams has gained us the credibility needed to be invited in to share in the evaluation, which is often done privately. The evaluation methodologies are different in each case in order to provide data that are useful to the course teams and their specific research questions. There are plans to publish each of these evaluations separately.

Health and Social Care is one of the largest academic schools, and in 2003/04 less than $10 \%$ of students studied modules that involved Mode 2 enhancements involving student-centred, interactive learning activities. In its e-learning strategy the school devoted significant, concentrated resources to developing three very large, undergraduate, interprofessional learning modules for Mode 2 enhancements. Effective interprofessional learning is both 'high stakes' and difficult to implement. Positive learning experiences may be confounded by negativity in professional practice (Barr, 2002) and students may transfer any negative perceptions of their educational experience into their professional practice (Freeth et al., 2002). The course team aimed to address this using online communication to promote and enhance knowledge construction in multi-professional teams. They developed the modules over the year with input from the school-based learning technologist, Media Workshop Learning 
Technologists and educational developers. As a result of this single, large-scale project, in 2004/05 approximately 30 school staff and over $40 \%$ of all Health and Social Care undergraduates were involved in Mode 2 use of the VLE. For example, the first-year Partnerships in Practice module was redesigned from a predominantly lecture format to teaching entirely through seminar groups working on collaborative assessed tasks. The group of approximately 300 students were divided into seminar groups that met face to face and had access to a range of discussion areas within the VLE where they worked through planned activities and prepared their assessed work. At the end of the module, feedback was collected from students in the form of a SPOT analysis, where students were asked to identify and agree in their subsets the top three Strengths, Possible improvements, Opportunities and Threats of the module. Students identified as strengths working in a multidisciplinary team, including the sharing of perspectives and opinions and WebCT as a way of communicating with groups and as a resource. Interviews were conducted with seven seminar group leaders concentrating on their changing roles as a face-to-face and online tutor and the changing relationships with their students.

The School of Business e-learning strategy emphasised core skills development, improved feedback to students on their learning and on module selection in the first year. A key development was diagnostic testing and formative online quizzes in a single, core, first-year module. This development involved $95 \%$ of first-year students, around $30 \%$ of the school's total undergraduate enrolment. The use of this computer-assisted diagnostic assessment provided students with guidance on the selection of their modules in their first year (Benfield \& Francis, 2004). A different example, in this case enhancing learning by incorporating learning activities contextualised to modern business practices, involves the Business School's Team Challenges module, which is taken by approximately two-thirds of all first years. In 2004 a 'virtual task' was introduced into the module that requires students to engage with a complex collaborative online task. The module leader reports a generally higher standard of reflection on team theory and students express high levels of satisfaction with the appropriateness and relevance of the new activities to the learning outcomes. Data are being collected through student focus groups and will be published separately. When we include several other smaller second-year and thirdyear Mode 2 developments in the 2004/05 academic year, the Business School increased the number of students working on Mode 2 enhanced modules from well below $10 \%$ to above $40 \%$.

A final example illustrates the different tempo and focus of developments in different schools. In 2003/04 the school of Biological and Molecular Sciences already had in place a significant Mode 1 web presence, in the form of a well-resourced intranet with key module and course information. There were several highly innovative Mode 2 enhanced modules but these engaged only very small numbers of students. In 2004/ 05 the school began to implement extensive online formative quizzes for first-year Biology students, giving them choices of when and where they can practise skills and obtain feedback on their learning. In just one year, from a negligible base, the school involved almost all of its first-year students in Mode 2 enhanced modules and well 
over one-third of all its undergraduate students overall. We are already seeing initial indications that retention of first-year students has increased, and this is under further investigation.

\section{Discussion: levers for change}

The usage data and examples of school-supported projects are evidence of the increased uptake of e-learning and, more importantly, its embedding within school teaching activities. The remaining focus for the evaluation was to explore the elements of the implementation activities that were most influential.

\section{Contextualisation}

The most influential lever for change has been the production of school e-learning strategies that allowed schools to set their plans for their own developments within their own context. Within the devolved organisational culture described earlier this allowed schools to follow their own paths rather than insisting on consistency across the institution. There were several particular features of the school strategy process worthy of note:

- Asking champions to devise their school's e-learning strategy ensured it was owned, local and relevant. We have seen a proactive culture emerging within schools taking their own responsibility for e-learning within their own domains rather than seeing it as being something that is done to them.

- Linking the staff development section to the existing annual staff development planning cycle and its associated funding enabled planning for e-learning to be integrated into existing university systems and associated the strategy writing process with a small amount of funding.

- The section of the template on rationale and goals led to a great deal of discussion and debate in some schools.

- The notion of 'school-supported projects' reduced the pressure on individual innovators to produce a successful project, involved greater numbers of staff and students and forced the issue of sustainability of e-learning within school systems and processes.

Schools have engaged with this process and it has led to a great deal of debate and discussion. Some schools conducted 'show and tell' sessions to provoke discussions on rationale, objectives and pedagogic philosophy for e-learning. For example, the Business School spent time sorting out their rationale through convening a series of meetings and discussions. The outcome of these was that:

The school's e-learning strategy ...emphasises the development of computer mediated communication whilst recognising quality content development may be required to add value to the learning experience. (OBU Business School, 2004)

The School of Health and Social Care, on the other hand, stated that: 
E-learning initiatives are based on constructivist/collaborative learning models. Online learning will be utilised to develop student-to-lecturer and peer-to-peer mentoring capabilities leading to awards that are competency-based, emphasising learning outcomes rather than teaching input. (OBU School of Health and Social Care, 2003, p. 4)

Several schools have now convened e-learning groups or committees to progress their work. Schools are now thinking more clearly about how to use e-learning and elearning activists are working hard on school-supported initiatives.

\section{Community}

Previous work has emphasised the importance of building supportive communities for innovators. In the 'hub and spokes' model used at Coventry University, teaching fellows came together in action learning sets, emphasising the importance of the informal and social aspects of this group. Although the initial aim of the appointment of teaching fellows was to create a critical mass of innovators, it quickly became apparent that the community was going to have more influence (Beaty et al., 2002). Similarly, Lee (2004) reports on staff development for 'innovative teaching and educational technology fellowship' holders that explicitly aimed to foster crossdisciplinary communities. As part of a comprehensive staff development programme for these fellows, they are split into groups of five or six that meet regularly to discuss each other's projects.

We worked hard to create a community within the learning technologists group. This is a difficult yet important task as naturally they identify first with the schoolbased communities they work in. However, for school learning technologists to be effective as 'brokers, taking practices from one context and introducing them to others' (Oliver, 2003, p. 265), it is vital that they identify with a similarly vibrant community of their own. The telling of stories and collective problem-solving are essential elements of communities of practice (Lave \& Wenger, 1991; Seely-Brown \& Duguid, 1991; Blackler, 1995). Effective communities circulate news and information, build and preserve new knowledge and express professional identity. Using data obtained from interviews with learning technologists, we have found that:

There is strong evidence that in the two years since the Learning Technologists' Forum was established a community of practice of learning technologists at Oxford Brookes University is emerging... . In many cases the school-based learning technologists have become firmly embedded in their schools. They are effective brokers of e-learning practice and agents of change in the University. (Benfield, in preparation)

Our learning technologists have monthly meetings, an email list, their own WebCT site and they participate as a group in professional development workshops. Noting that a characteristic of communities of practice is mutual engagement, Oliver (2003, p. 263) comments that, for some groups of learning technologists 'the intensity of these engagements is questionable'. To address this problem the Learning Technologists Forum works on university-wide projects and issues. For example, this group successfully lobbied for the university's adoption of the CourseGenie web content development tool and supports its use; it is a source of examples of good e-learning practice 
that are disseminated through the university's Open Exemplar database; and it has driven enhancements to the exchange of data between the VLE and the student management system.

\section{Teachers' beliefs}

Our focus on working with school-supported projects and course teams enabled us to focus on educational decisions before the technical ones. We consider it vital to tackle real educational issues rather than hypothetical ones. Where Hanson (2003) conducted focus groups with staff to understand their attitudes and motivations to use technology, we took the importance of changing perceptions as a theme throughout all our development work. The modes of engagement focused on individual teachers' beliefs, the school strategies on Deans' beliefs, and the course design intensive session on course team beliefs. For example, in feedback about one of the intensive events participants commented that they valued the following:

Enforcing the course team to consider some absolutely fundamental issue relating to course design.

Thinking critically about our programme.

Provoking thoughts on the purpose of teaching, learning and assessment generally.

Opportunity to do this as an identified staff team-useful as a team building exercise.

All of these staff development methods were about changing perceptions of what could be done. Similarly, Errington (2004), in looking at staff development for flexible delivery at Massey University, New Zealand, postulated that adoption or rejection of innovation is likely to be due to beliefs as much as it is due to infrastructure. $\mathrm{He}$ recommends that staff development engages teachers in dialogue about their personal theories of learning and teaching, acknowledging their fears and matching this with theoretical perspectives and offering appropriate support.

\section{Conclusions}

The initial aim of this project was to develop an implementation plan that would not only increase the uptake of e-learning at the institution, but promote the development of effective and sustainable e-learning courses. It can be seen from the combination of the usage data and the illustrative examples that within some academic schools a large and increasing proportion of students are now experiencing blended learning. A number of detailed evaluations are underway to assess the ways in which teaching and learning has been enhanced through Mode 2 level of engagements.

In this paper we have reflected on the development activities undertaken to implement the university e-learning strategy. The implementation plan was always intended to be based on existing recommendations for the adoption of learning technology and, as such, some of our successes confirm what makes for effective development interventions. We identified specific activities that were successful, but noted that this was 
likely to be due to some elements of effective interventions: contextualisation, community and teachers' beliefs, rather than the activities per se. For example, we found that asking schools to write their own strategies was helpful, and argued that this was because emphasis at the school level fitted what was needed within our institutional context and promoted the discussion and debate that influences individual teachers' beliefs. Not all of our experiences and reflections are so easily apparent from the available literature. It is noted that in our case school-level strategies achieved buy-in (rather than strategy fatigue), the learning technologists went beyond being influential as individuals to developing as a community of brokers and that engaging developers in targeted, contextualised staff development impacted favourably on implementation and evaluation.

In line with our original analysis of context, we aimed to move away from successful, but small innovative projects that depended on a single enthusiast. Now our school-based developments often continue to be lead and driven by our innovators, but they are not solely dependent on them for their implementation. It is anticipated that the courses will be sustainable in the long term as they are supported by their Deans, their local strategy for e-learning and central and school-based learning technologists and developers.

\section{References}

Banks, S. \& Powell, A. (2002) Developing institutional readiness for implementing networked learning, Networked Learning Conference Proceedings, 26-28 March 2002, pp. 41-46.

Barr, H. (2002) Interprofessional education today, yesterday and tomorrow: a review, Learning and Teaching Support Network Centre for Health Sciences and Practice. Available online at: http:// www.health.heacademy.ac.uk/publications/occasionalpaper/occasionalpaper01.pdf (accessed 23 January 2006).

Baume, A. D. (1996) IT Term at Oxford Brookes University — an evaluation. Internal report, October.

Beaty, E., Cousin, G. \& Deepwell, F. (2002) Introducing e-learning via a community network: a teaching and learning strategy in action, Networked Learning Conference Proceedings, 26-28 March 2002, pp. 36-40.

Beetham, H. \& Bailey, P. (2002) Professional development for organisational change, in: R. Macdonald \& J. Wisdom (Eds) Academic and educational development: research, evaluation and changing practice in higher education (London, Kogan Page), 164-176.

Bell, M., Bush, D., Nicholson, P., O'Brien, D. \& Tran, T. (2002) Universities online: a survey of online education and services in Australia. Commonwealth Department of Education Science and Training, Higher Education Group. Available online at: http://www.dest.gov.au/sectors/ higher_education/publications_resources/summaries_brochures/universities_online.htm (accessed 27 May 2005).

Benfield (in preparation) A case study of an emerging community of practice: learning technologists embedded in academic schools.

Benfield, G. \& Francis, R. (2004) Perspectives on e-learning at Brookes, Brookes e-fournal of Learning and Teaching, 1(2). Available online at: http://www.brookes.ac.uk/publications/bejlt/ volume1 issue2/perspective/benfield_francis.html! (accessed 27 May 2005).

Blackler, F. (1995) Knowledge, knowledge work and organizations: an overview and interpretation, Organization Studies, 16(6), 1021-1046.

Browne, T. \& Jenkins, M. (2003) VLE surveys: a longitudinal perspective between March 2001 and March 2003 for higher education in the United Kingdom. Available online at: www.ucisa.ac.uk/ groups/tlig/vle/index_html (accessed 27 May 2005). 
Challis, L. \& Lidgey, J. (2000) Brookes' virtual dimension, Teaching Forum, Summer. Available online at: http://www.brookes.ac.uk/virtual/NewTF/48/tf_48lead.htm (accessed 28 April 2005).

Collis, B. \& De Boer, W. (1999) Scaling up from the pioneers: the TeleTOP method at the University of Twente, Interactive Learning Environments, 7(2-3), 93-111.

Conole, G., Dyke, M., Oliver, M. \& Seale, J. (2004) Mapping pedagogy and tools for effective learning, Computers and Education, 43, 17-33.

Dempster, J. \& Deepwell, F. (2003). Experiences of national projects in embedding learning technology into institutional practices, in: J. K. Seale (Ed.) Learning technology in transition: from individual enthusiasm to institutional implementation (Lisse, Swets \& Zeitlinger), $45-62$.

Errington, E. (2004) The impact of teacher beliefs on flexible learning innovation: some practices and possibilities for academic developers, Innovations in Education and Teaching International, 41(1), 39-47.

Fitz, J., Halpin, D. \& Power, S. (1994) Implementation research and education policy: practice and prospects, British Fournal of Educational Studies, 42(1), 53-69.

Freeth, D., Hammick, M., Koppel, I., Reeves, S. \& Barr, H. (2002) A critical review of evaluations of interprofessional education, Learning and Teaching Support Network Centre for Health Sciences and Practice. Available online at: http://www.health.ltsn.ac.uk/publications/occasionalpaper/occasionalpaper02.pdf\%20 (accessed 23 November 2005).

Garrison, R. \& Anderson, T. (2003) E-learning in the 21st century: a framework for research and practice (London, RoutledgeFalmer).

Gibbs, G. (1999) Institutional learning and teaching strategies: a guide to good practice. Circular 99/55, Higher Education Funding Council for England.

Hannan, A. \& Silver, H. (2000) Innovating in higher education: teaching, learning and institutional cultures (Buckingham, SRHE and Open University Press).

Hanson, J. (2003) Encouraging lecturers to engage with technologies in learning and teaching in a vocational university: the role of recognition and reward, Higher Education Policy and Management, 15(3), 135-149.

Laurillard, D. (2001) The e-university: what have we learned?, The International fournal of Management Education, 1(2), 3-7.

Lave, J. \& Wenger, E. (1991) Situated learning: legitimate peripheral participation (Cambridge, Cambridge University Press).

Lee, A. (2004) Institutional approaches to e-learning: UNSW and the ITET fellowship, HERSDA News, April.

Lisewski, B. (2004) Implementing a learning technology strategy: top-down strategy meets bottom-up culture, ALT-f, 12(2), 175-188.

Newton, J. (2003) Implementing an institution-wide learning and teaching strategy: lessons in managing change, Studies in Higher Education, 28(4), 427-441.

Oliver, M. (2002) What do learning technologists do?, Innovations in Education and Teaching International, 39(4), 1-8.

Oliver, M. (2003). Community, identity and professionalisation: are learning technologists a community of practice?, paper presented at the Research Proceedings of the 10th Association for Learning Technology Conference (ALT-C 2003), University of Sheffield and Sheffield Hallam University, 8-10 September.

Oliver, M. \& Dempster, J. (2003) Embedding e-learning practices, in: R. Blackwell \& P. Blackmore (Eds) Towards strategic staff development in higher education (Buckingham, SRHE and Open University Press), 142-153.

OBU Business School (2004) Business school e-learning strategy-approved LATEC-fune 2004. Internal report, June.

OBU School of Health and Social Care (2003) Oxford Brookes University School of Health and Social Care e-learning strategy 2003-2005. Internal report, May 2003. 
Seely-Brown, J. \& Duguid, P. (1991) Organizational learning and communities of practice: toward a unified view of working, learning, and innovation, Organization Science, 2(1), 40-57.

Staley, A. \& MacKenzie, N. (Eds) (2001) Computer supported experiential learning (Birmingham, Learning Methods Unit, University of Central England). Available online at: http:// www.ssdd.uce.ac.uk/research/csel-book/CSEL-book.pdf (accessed 26 May 2005).

Stiles, M. (2004) Is an eLearning strategy enough?, Educational Developments, 5(1), 13-15.

Stiles, M. \& Yorke, J. (2003) Designing and implementing learning technology projects-a planned approach, workshop paper presented for the EFFECTS-Embedding Learning Technologies Seminar, University College London, 8 April. Available online at: http://www.jiscinfonet.ac.uk/ Resources/external-resources/eltfinal.doc/view (accessed 27 May 2005).

Trowler, P. (1998) Academics responding to change: new higher education frameworks and academic cultures (Buckingham, SRHE and Open University Press).

Wills, S. \& Alexander, S. (2000) Managing the introduction of technology in teaching and learning, in: T. Evans, \& D. Nation (Eds) Changing university teaching: reflections on creating educational technologies (London, Kogan page), 56-72. 